\title{
Job Satisfaction of U.A.E. Dental Practitioners
}

\author{
Manal Awad ${ }^{3}$ \\ ${ }^{1}$ Dental and Maxillofacial Department, Royal Medical Services, \\ Bahrain Defense Force Hospital, West Riffa, Kingdom of Bahrain \\ ${ }^{2}$ College of Dental Medicine, University of Sharjah, Sharjah, United \\ Arab Emirates \\ ${ }^{3}$ Department of Preventive and Restorative Dentistry, College \\ of Dental Medicine, University of Sharjah, Sharjah, United Arab \\ Emirates
}

Fajer S. Al-Buainain ${ }^{1}$ Asma A. Alzarouni ${ }^{2}$ Hissa A. Alshamsi ${ }^{2}$ Arwa H. Arab ${ }^{2}$ Fares Bader ${ }^{2}$

Eur J Dent 2019;13:354-360

\begin{abstract}
Address for correspondence Fajer Salem Al-Buainain, BDS, MFD, Dental \& Maxillofacial Centre, Royal Medical Services, Bahrain Defence Force, P.O. Box, 28743, West Riffa, Kingdom of Bahrain (e-mail: Fajer.s.albuainain@gmail.com).
\end{abstract}

\begin{abstract}
Keywords

- job satisfaction

- dentist

- public sector

- private sector

- work environment factors

Objective The study aims to analyze job satisfaction among registered clinical dentists in the United Arab Emirates (UAE), and also to explore satisfaction with different work environmental factors and relate them to overall job satisfaction.

Materials and Methods A survey modified from the American Dental Association version of job satisfaction published in 2013 to 2014, was given to 197 licensed dentists in Dubai and Sharjah cities in the UAE. The questionnaire included four main sections, in addition to the demographic factors questions. All questions were answered using the 5-point Likert scale. The only exception was the comfortability in the working environment which was answered using a 3-point Likert scale.

Statistical Analysis Categorical data were presented as frequencies and percentages, and data were analyzed using means and standard deviations. Regression analysis was performed with overall job satisfaction as the dependent variable and seven aspects of satisfaction with work and individual characteristics as the independent variables. An $\alpha$ level of 0.05 was used for tests of statistical significance.

Results The overall job satisfaction of dentists working in the UAE is high compared with other countries. Highest satisfaction was related to the relationship with patients, colleagues, and staff. On the other hand, the least satisfaction was linked to the opportunity for part-time work and benefits package. There were no significant differences between male and female participants regarding all work-related factors apart from autonomy. However, private sector dentists had a higher level of satisfaction compared with the public sector in many work-related factors.

Conclusion There are various dimensions that collectively influence the level of overall job satisfaction. Difference existing between the levels of job satisfaction among private and public sector dentists and between male and female dentists need to be addressed to increase the level of job satisfaction among UAE dentists and thus improve all dental care system.
\end{abstract}

\section{Introduction}

Job satisfaction has been described as the "positive emotional state resulting from the appraisal of one's job or job experience." The concept was also defined by Mausner, where he made the distinction between intrinsic satisfactions that included recognition, the work tasks themselves, and the level of responsibility. Furthermore, extrinsic factors, such as working conditions, income, and company policy, were also previously identified as correlated of job satisfaction. ${ }^{2}$ It is an 
important issue because dentistry has been identified as one of the most stressful professions, with low job satisfaction being a contributing factor to stress and burn out. ${ }^{3-6}$ Moreover, evidence suggests that engaged workers with high job demands are more creative, more productive, and more willing to go "the extra mile."

The perception of high job satisfaction is not only an individual matter for the dentists, but it also provides a positive external outcome for patients and organizations, ${ }^{8}$ as low job satisfaction is associated with low performance, suboptimal health care delivery, and clinical outcomes of primary care providers. Subsequently, this can lead to loss of continuity of care.,10

Dentists in different countries have shown different levels of satisfaction regarding their careers. For example, $82.6 \%$ of the Australian dentists and $80.7 \%$ of the Lithuanian dentists were highly satisfied with various aspects of their jobs. While, 51\% of the Korean dentists and 51.4\% of the Egyptian dentist were neutral with regards to their job satisfaction. ${ }^{1,5,11,12}$ The lowest levels of job satisfaction were reported in Iran, where the mean satisfaction scores were relatively low (1.5 out of 5) which indicates that dentists in Iran may find their jobs to be stressful. ${ }^{13}$

A relatively fewer studies were conducted in the United Arab Emirates (UAE) regarding dentists' well-being. ${ }^{14,15}$ These studies aimed to investigate the prevalence of medical problems that are common among dentists, such as occupation-related health problems, ${ }^{14}$ or lifestyle-induced conditions. ${ }^{15}$ Only recently there has been increased interest in the assessment of dentists' satisfaction with their jobs, because of its possible impact on their productivity and well-being. In 2018, a study was conducted to assess the quality of life (QOL) among 290 dentists in the UAE, and the findings indicated that QOL of dentists in the UAE can be affected by several factors such as social status and degree possessed. ${ }^{16}$

Therefore, the aim of our study is to assess the overall job satisfaction of dentists working in the UAE and associated factors.

\section{Materials and Methods}

\section{Study Sample}

The study population included 197 licensed dentists working in private and public sectors in the Emirates of Dubai and Sharjah. Multiple lists of licensed dentists were obtained from various authorities in Sharjah and Dubai. The study sample excluded university staff and nonworking dentists. The study was conducted in the period between November 2016 and April 2017. Practicing dentists in private and public sectors were approached and asked to respond to the questionnaire. The questionnaire included an introduction letter assuring the participating dentists that their personal information will remain confidential. All dentists had to sign a consent form prior to responding to the questionnaire.

\section{Study Design and Questionnaire}

The study utilized a cross-sectional survey of registered dentists in Dubai and Sharjah cities. The survey is modified from the American Dental Association (ADA) version of job satisfaction published in 2013 to 2014 . The questionnaire is valid and has been used earlier by ADA. ${ }^{17}$
The questionnaire included four sections: the first section contains a set of questions pertaining to the general feelings of the dentists and their overall satisfaction about dentistry as a profession. The second section is concerned with the participant's satisfaction in correspondence to their hours/ scheduling, work-life balance, and career advancement/skill development. The third section covers the autonomy and the relationship of dentists with various parties including staff, colleagues, and patients. This section consists of two questions, the first question asks about how comfortable the dentist is in his/her working environment, while the second question asks about the dentists' satisfaction in general toward their patients, colleagues, and staff. The fourth section focuses on the dentists' income.

All questions were answered using a 5-point Likert scale ( 5 = very satisfied, $4=$ moderately satisfied, $3=$ neither satisfied nor dissatisfied, 2 = moderately dissatisfied, 1 = very dissatisfied), the midpoint result is 3 and thus mean scale score greater than 3 was taken to represent agreement. ${ }^{1}$ The only exception is the comfortability in the working environment which was answered using 3 -point Likert scale ( $1=$ comfortable, 2 = either comfortable or uncomfortable, 3 = uncomfortable).

\section{Data Analysis}

Seven main variables were assessed in the study; the overall satisfaction in the dental profession in general and satisfaction with six work-related factors, specifically "time," "scheduling," "control," "autonomy and relationships," "income," and "benefits." Each variable was assessed using more than one question, and the responses were weighted individually.

Data analysis was performed using SPSS (version 21). Categorical data were presented as frequencies and percentages, and for continuous variables data were analyzed using means and standard deviations.

Additional regression analysis was performed with overall job satisfaction as the dependent variable and seven aspects of satisfaction with work and individual characteristics as the independent variables. An $\alpha$ level of 0.05 (two-tailed) was used for tests of statistical significance.

\section{Ethical Approval}

The study was conducted in full accordance with the World Medical Association Declaration of Helsinki and received ethical approval from the Research and Ethics committee of College of Dental Medicine, University of Sharjah.

\section{Results}

\section{Participants}

In this study, a total of 197 questionnaires were completed providing a response rate of $71 \%$. The characteristics of the sample population are presented in ( - Table $\mathbf{1})$. Higher proportion of respondents was in the young age group with over half of them aged 24 to 35years (52.8\%). Forty-four percent $(N=87)$ of the respondents were males and $55.8 \%(N$ $=110$ ) were females. Almost two-thirds of the participants were from the private sector (63.5\%), and $36.5 \%$ were from the public sector. The majority of the respondents indicated 
Table 1 Characteristics of dentists' sample

\begin{tabular}{|l|l|l|l|}
\hline \multicolumn{2}{|c|}{} & $\begin{array}{l}\text { Frequency } \\
(\boldsymbol{n})\end{array}$ & $\begin{array}{l}\text { Percentage } \\
\%\end{array}$ \\
\hline \multirow{4}{*}{ Gender } & Male & 87 & 44.2 \\
\cline { 2 - 4 } & Female & 110 & 55.8 \\
\hline \multirow{5}{*}{ Age group (y) } & $24-35$ & 103 & 52.8 \\
\cline { 2 - 4 } & $35-45$ & 60 & 30.8 \\
\cline { 2 - 4 } & $45-55$ & 24 & 12.2 \\
\cline { 2 - 4 } & 55 and above & 8 & 4.1 \\
\hline \multirow{5}{*}{ Type of practice } & Single & 60 & 30.5 \\
\cline { 2 - 4 } & Married & 121 & 61.4 \\
\cline { 2 - 4 } & Divorced & 10 & 5.1 \\
\cline { 2 - 4 } & Widowed & 1 & 0.5 \\
\hline \multirow{5}{*}{ Degree possessed } & Public & 72 & 36.5 \\
\cline { 2 - 4 } & Private & 125 & 63.5 \\
\hline \multirow{5}{*}{ Years of clinical experience (y) } & BDS/DDS & 133 & 67.5 \\
\cline { 2 - 4 } & MSc & 50 & 25.4 \\
\cline { 2 - 4 } & PhD & 9 & 4.6 \\
\cline { 2 - 4 } & 5 or less & 61 & 31 \\
\cline { 2 - 4 } & 5-10 & 49 & 24.9 \\
\cline { 2 - 4 } & $10-15$ & 37 & 18.8 \\
\cline { 2 - 4 } & 15 or more & 39 & 19.8 \\
\hline
\end{tabular}

Abbreviations: BDS, Bachelor of Dental Surgery; DDS, Doctor of Dental Surgery; MSc, Master of Science; PhD, Doctor of Philosophy.

that "general practice" was their main area of practice and $30 \%(N=59)$ were specialists.

Mean scale score of greater than 3 was chosen to represent agreement, and this score was used to measure various aspect of job satisfaction. The level of overall mean job satisfaction of dentists working in the UAE was $3.7 \pm 1$.2, indicating that the respondents were satisfied with various aspects of their job as a dentist ( - Table 2).

The three highest scores reported by the dentists were for their relationship with patients, colleagues, and staff with a score of $3.7 \pm 1.0,3.7 \pm 1.3$, and $3.7 \pm 1.2$, respectively. Most of them responded that they are comfortable in their working environment (mean score $=1.3 \pm 0.6$ ).

In this study, among all work-related factors, dentists showed the least satisfaction with opportunity for part-time work, as it had the lowest mean score of $2.8 \pm 1.4$ out of 5 . The second lowest evaluated practice area was related to the perception of benefits package related to insurance, retirement, and bonuses with a satisfaction score of $2.9 \pm 1.4$ out of 5 .

No significant difference between male and female participants were observed regarding all work-related factors except for autonomy ( - Table $\mathbf{3}$ ), in which male dentists were more comfortable in their working environment compared with female dentists $(1.3 \pm 0.5$ and $1.4 \pm 0.6$, respectively, $p=0.01$ ). Furthermore, male dentists expressed higher levels of satisfaction in their relationships with other dentist colleagues (males: $4.0 \pm 1.0$ vs. females: $3.4 \pm 1.3$ ) and staff (males: $3.9 \pm 1.1$ / females: $3.5 \pm 1.3)(p<0.001)$.
- Table 4 compares between dentists in the private and public sectors. Dentists practicing in private sectors were more satisfied compared with those practicing in the public sector regarding vacation scheduling (private: $3.1 \pm 1.1$ / public: $3.0 \pm 1.5, p=0.00$ ) and opportunities for advancements (private: $2.8 \pm 1.4$ / public: $2.7 \pm 1.3, p=0.00$ ). However, the general overall satisfaction for both private and public sector dentists was still on the agreement side of the midpoint, indicating an overall level of satisfaction (private: $3.8 \pm 1.2$ / public: $3.5 \pm 1.2, p=0.00$ ).

Dentists who work in the private sector were more satisfied with their income, compared with those in the public sector (private: mean $=3.5 \pm 1.0$ / public: mean $=2.9 \pm 1.3 ; p=0.02$ ),

Despite the higher level of satisfaction of dentists in the private sector with part-time work opportunities, both groups had a mean score that is below 3, indicating an overall dissatisfaction with part-time work job opportunities (private: mean $=2.8 \pm 1.4$ / public: mean $=2.7 \pm 1.3, p=0.05$ ).

The comfortability in the working environment was significantly higher for the private sector dentists (mean: $1.2 \pm 0.5$ ) compared with the dentist of public sector (mean: $1.5 \pm 0.7)(p=0.00)$.

- Table 5 depicts the results of the linear regression analysis of the association between overall satisfaction and the independent variables. The dentists' years of clinical experience was associated with significantly higher levels of overall satisfaction $(B=0.38,95 \%$ confidence interval: $0.14,0.62 ; p<0.001)$. 
Table 2 Overall mean dimension scores for job satisfaction

\begin{tabular}{|c|c|c|}
\hline & Mean & $\begin{array}{l}\text { Standard } \\
\text { deviation }\end{array}$ \\
\hline $\begin{array}{l}\text { Overall, dentist satisfaction with their } \\
\text { career }\end{array}$ & 3.7 & 1.2 \\
\hline \multicolumn{3}{|l|}{$\begin{array}{l}\text { Working related factors } \\
1 \text { - Scheduling }\end{array}$} \\
\hline Opportunity for part-time work & 2.8 & 1.4 \\
\hline Vacation & 3.1 & 1.3 \\
\hline \multicolumn{3}{|l|}{ 2- Benefits } \\
\hline $\begin{array}{l}\text { Benefits package (insurance, retirement, } \\
\text { bonuses, etc.) }\end{array}$ & 2.9 & 1.4 \\
\hline $\begin{array}{l}\text { The level of support received for partici- } \\
\text { pation in your organization }\end{array}$ & 3.3 & 1.3 \\
\hline Opportunities for advancements & 3.4 & 1.2 \\
\hline \multicolumn{3}{|l|}{ 3- Control } \\
\hline $\begin{array}{l}\text { The level of control in working } \\
\text { environment }\end{array}$ & 3.4 & 1.1 \\
\hline $\begin{array}{l}\text { Satisfaction with participation in organi- } \\
\text { zational decision-making }\end{array}$ & 3.5 & 1.2 \\
\hline \multicolumn{3}{|l|}{ 4- Income } \\
\hline Satisfaction with salary & 3.3 & 1.2 \\
\hline $\begin{array}{l}\text { Pleased with income in comparison to } \\
\text { other dentists }\end{array}$ & 3.4 & 1.2 \\
\hline \multicolumn{3}{|l|}{ 5- Autonomy and relationships } \\
\hline $\begin{array}{l}\text { Comfortability in the working } \\
\text { environment }\end{array}$ & 1.3 & 0.6 \\
\hline Patients relation & 3.7 & 1.0 \\
\hline Dentist colleagues & 3.7 & 1.3 \\
\hline $\begin{array}{l}\text { Staff (dental assistants, oral hygienists, } \\
\text { secretaries, cleaners, etc.) }\end{array}$ & 3.7 & 1.2 \\
\hline
\end{tabular}

Compared with single dentists, married dentists were significantly less satisfied ( $B=-0.41,95 \% \mathrm{CI}:-0.75,-0.08$ ). There is a positive association between the level of income satisfaction and the overall satisfaction.

\section{Discussion}

Dentistry is considered to be one of the most stressful professions $^{3-5}$ with the overall job satisfaction varying between countries. ${ }^{10-19}$ This study was conducted to assess the overall job satisfaction among working dentists in the UAE and to assess the effect of sociodemographic factors and work environment factors on their level of satisfaction.

UAE dentists had an overall average satisfaction rating of $3.7 \pm 1.2$ out of 5 , which is relatively high compared with other countries. For example, the overall job satisfaction among dentists in a neighboring country, Iran, was reported relatively lower; issues such as salary and remuneration, facilities, equipment, and tenure policies are strongly believed to account for the dentists' dissatisfaction. ${ }^{13}$ To the contrary, the high level of overall satisfaction among dentist in the UAE is most likely influenced by the nation and the government itself ${ }^{20}$ according to the First World Happiness Report (2012) which measures wealth, economic activity, social relations, and public welfare, UAE was the 17th happiest country. ${ }^{21}$ Moreover, in 2013 societal values survey proposed that the UAE is considered to be the second least negative country in the world. ${ }^{22}$

In this study, dentists were most satisfied with their relationship with the patients, other colleagues, and staff member in addition to the autonomy in their practice. This finding is consistent with previous studies as $78 \%$ of the participants in Egypt and $77.9 \%$ of the participants in Korea were satisfied in their relationships with patients. ${ }^{11,12}$ On the other hand, dentists were least satisfied with the opportunity for parttime work. Followed by their perception of benefit packages related to insurance, retirement, and bonuses; a possible explanation for this observation is that most of the younger dentists in this study (52.8\%) are more likely working with short- or medium-term contracts, which may affect their retirement plans, thus, it can cause a major stress to the dentists. However, employment status data were not collected in this study, which makes it difficult to ascertain the reason for this observation. To the contrary, the most important distressing factor in other studies conducted in other countries was found to be the long working hours. ${ }^{11,12}$ This suggests that despite the similarities in every day practice, there are factors that may influence health professionals' satisfaction that could be unique to each culture/society.

Consistent with previous studies, ${ }^{1,12,13}$ significant differences were observed between males and females in terms of autonomy and relationships, with females having lower autonomy scores compared with males. This finding can be explained by the fact that female dentists scored less than males in regard to their perceived level of control in the working environment and their participation in organizational decision-making which might cause them to be less comfortable in that environment in general.

On the contrary, a study conducted in India found that females were significantly more satisfied with their staff. ${ }^{16}$ The time dimension constituted a significant difference between genders with females having more personal time off and more flexibility in their hours in several studies conducted in Australia, ${ }^{1}$ India, ${ }^{18}$ and New Zealand. ${ }^{23}$ It was explained by the fact that many female dentists work less than full-time, with the reason for part-time practice given by women was caring for children. ${ }^{23}$ However, such differences were not observed in our study, and it might be explained by the fact that part-time jobs are much less popular in the UAE, which is consistent with the fact that dentists showed a low satisfaction with opportunity for part-time work, as it had the lowest mean score, among all work-related factors.

No significant difference was found in the overall job satisfaction among dentists practicing in the private and public sectors. However, dentists in the private sector showed significantly higher satisfaction in several aspects such as time for vacations and part-time jobs. Which can be explained by the flexibility the private sector offers, furthermore, dentists in the private sector may be business owners which give them the freedom to advance their knowledge by attending 
Table 3 Job satisfaction score by gender

\begin{tabular}{|c|c|c|c|c|c|}
\hline & \multicolumn{2}{|c|}{ Male } & \multicolumn{2}{|c|}{ Female } & \multirow[t]{2}{*}{$p$-Value } \\
\hline & Mean & SE & Mean & SE & \\
\hline Overall, dentist satisfaction with their career & 3.9 & 1.1 & 3.6 & 1.2 & 0.61 \\
\hline \multicolumn{6}{|l|}{$\begin{array}{l}\text { Working related factors } \\
1 \text { - Scheduling }\end{array}$} \\
\hline Opportunity for part-time work & 3.1 & 1.4 & 3.0 & 1.3 & 0.8 \\
\hline Vacation & 3.3 & 1.2 & 3.0 & 1.3 & 0.17 \\
\hline \multicolumn{6}{|l|}{ 2- Benefits } \\
\hline Benefits package (insurance, retirement, bonuses, etc.) & 3.0 & 1.4 & 2.9 & 1.4 & 0.72 \\
\hline The level of support received for participation in your organization & 3.5 & 1.2 & 3.2 & 1.3 & 0.69 \\
\hline Opportunities for advancements & 3.6 & 1.1 & 3.1 & 1.2 & 0.81 \\
\hline \multicolumn{6}{|l|}{ 3- Control } \\
\hline The level of control in working environment & 3.7 & 1.1 & 3.2 & 1.1 & 0.50 \\
\hline Satisfaction with participation in organizational decision-making & 3.8 & 1.1 & 3.3 & 1.2 & 0.43 \\
\hline \multicolumn{6}{|l|}{ 4- Income } \\
\hline Satisfaction with salary & 3.5 & 1.1 & 3.1 & 1.2 & 0.89 \\
\hline Pleased with income in comparison to other dentists & 3.6 & 1.1 & 3.1 & 1.3 & 0.30 \\
\hline \multicolumn{6}{|l|}{ 5- Autonomy and relationships } \\
\hline Comfortability in the working environment & 1.3 & 0.5 & 1.4 & 0.6 & 0.01 \\
\hline Patients relation & 3.9 & 1.0 & 3.5 & 1.0 & 0.47 \\
\hline Dentist colleagues & 4.0 & 1.0 & 3.4 & 1.3 & 0.00 \\
\hline Staff (dental assistants, oral hygienists, secretaries, cleaners, etc.) & 3.9 & 1.1 & 3.5 & 1.3 & 0.00 \\
\hline
\end{tabular}

Abbreviation: SE, standard error.

conferences and workshops, while in the public sector personal time off maybe needed to attend such events, leading to fewer opportunities to advance their knowledge.

Both sectors were satisfied with their income with significantly higher scores in the private sector, the difference may be due to more fixed income in the public sector while the private sector can offer higher wages and bonuses. Dentists in the private sector were also more comfortable in their environment scoring higher in autonomy, similar results were also found in the U.K., Australia, Sweden, and Denmark. 1,24,25 Higher autonomy scores can be explained by funding limitations within the public sector as other studies concluded that the public sector dentists are more limited in their resources and the treatments they can offer to the patient which can contribute to their dissatisfaction.

Unlike previous reports from other countries, ${ }^{1,12}$ age was not a significant predictor of dentists' overall satisfaction. However, the number of years of clinical experience was a strong predictor of job satisfaction. Increased satisfaction with more years of experience can be related to increased knowledge and skills to manage the patients and build rapport. In addition to that, they will be able to cope with the workload in a more positive manner. Another possible cause, is that with increased clinical experience most dentists have a better job position or a higher academic degree, which is associated with a better QOL. ${ }^{16}$
Contrary to previous reports, in this study, single participants were more satisfied with their jobs compared with married dentists. ${ }^{16,18,26-29}$ Single dentists may have more freedom in other aspects of their life and less responsibilities, and therefore, they are able to cope with the stress of their profession.

This study can be instrumental in initiating policy changes in the UAE. It highlights strengths and drawbacks in the profession as viewed by the dentists themselves. In general, dentists in the public sector reported lower satisfaction in comparison to the public sector which can have an impact on the availability of dentists in the public sector in favor of the private sector. On the long term, this could affect the health care system in general and will compromise patient's care in the public sector.

Limitations of this study include the relatively small sample size. The response rate for the study is relatively high (71\%); however, it is possible that dentists who refused to participate in the study could be different in their ratings of satisfaction compared with those who agreed to participate.

\section{Conclusion}

Our findings indicate that the level of overall job satisfaction of dentists working in the UAE was high in comparison to other countries. Highest satisfaction was for the relationship with patients, colleagues, and staff, while the least satisfaction was related to opportunity for part-time work and 
Table 4 Type of current primary practice (public/private)

\begin{tabular}{|c|c|c|c|c|c|}
\hline & \multicolumn{2}{|c|}{ Public } & \multicolumn{2}{|c|}{ Private } & \multirow[t]{2}{*}{$p$-Value } \\
\hline & Mean & SE & Mean & SE & \\
\hline Overall, dentist satisfaction with their career & 3.5 & 1.2 & 3.8 & 1.2 & 0.22 \\
\hline \multicolumn{6}{|l|}{$\begin{array}{l}\text { Working related factors } \\
1 \text { - Scheduling }\end{array}$} \\
\hline Opportunity for part-time work & 2.7 & 1.3 & 2.8 & 1.4 & 0.05 \\
\hline Vacation & 3.0 & 1.5 & 3.1 & 1.1 & 0.00 \\
\hline \multicolumn{6}{|l|}{ 2- Benefits } \\
\hline Benefits package (insurance, retirement, bonuses, etc.) & 2.8 & 1.5 & 3.0 & 1.3 & 0.18 \\
\hline The level of support received for participation in your organization & 3.1 & 1.2 & 3.5 & 1.3 & 0.07 \\
\hline Opportunities for advancements & 3.0 & 1.0 & 3.5 & 1.2 & 0.02 \\
\hline \multicolumn{6}{|l|}{ 3- Control } \\
\hline The level of control in working environment & 3.2 & 1.0 & 3.6 & 1.0 & 0.39 \\
\hline Satisfaction with participation in organizational decision-making & 3.2 & 1.1 & 3.7 & 1.2 & 0.12 \\
\hline \multicolumn{6}{|l|}{ 4- Income } \\
\hline Satisfaction with salary & 2.9 & 1.3 & 3.5 & 1.0 & 0.02 \\
\hline Pleased with income in comparison to other dentists & 3.0 & 1.4 & 3.5 & 1.1 & 0.04 \\
\hline \multicolumn{6}{|l|}{ 5- Autonomy and relationships } \\
\hline Comfortability in the working environment & 1.5 & 0.7 & 1.2 & 0.5 & 0.00 \\
\hline Patients relation & 3.4 & 1.0 & 3.8 & 1.0 & 0.90 \\
\hline Dentist colleagues & 3.3 & 1.2 & 3.9 & 1.3 & 0.98 \\
\hline Staff (dental assistants, oral hygienists, secretaries, cleaners, etc.) & 3.5 & 1.3 & 3.8 & 1.2 & 0.59 \\
\hline
\end{tabular}

Abbreviation: SE, standard error.

Table 5 Relation between overall job satisfaction and the following variables

\begin{tabular}{|c|c|c|c|c|}
\hline Variables & $B$ & $p$-Value & \multicolumn{2}{|c|}{ 95\% confidence interval } \\
\hline $\begin{array}{l}\text { Gender } \\
\text { - Male } \\
\text { - Female }\end{array}$ & -0.057 & 0.75 & -0.41 & 0.30 \\
\hline $\begin{array}{l}\text { Social status } \\
\text { - Single } \\
\text { - Married }\end{array}$ & -0.41 & 0.01 & -0.75 & -0.08 \\
\hline $\begin{array}{l}\text { Type of practice } \\
\text { - Public } \\
\text { - Private }\end{array}$ & 0.02 & 0.899 & -0.34 & 0.39 \\
\hline $\begin{array}{l}\text { Clinical experience }(\mathrm{y}) \\
\text { - } 5 \text { or less } \\
\text { - } 5-10 \\
\text { - } 10 \text { or more }\end{array}$ & 0.38 & 0.00 & 0.14 & 0.62 \\
\hline $\begin{array}{l}\text { Contract type } \\
\text { - Full-time } \\
\text { - Part-time }\end{array}$ & 0.54 & 0.11 & -0.12 & 1.20 \\
\hline $\begin{array}{l}\text { Degree } \\
\text { - } \mathrm{BDS} / \mathrm{DDS} \\
\text { - } \mathrm{MSC} \\
\text { - } \mathrm{PhD}\end{array}$ & 0.04 & 0.67 & -0.15 & 0.24 \\
\hline $\begin{array}{l}\text { Satisfaction with income } \\
\text { - Dissatisfied } \\
\text { - Neither satisfied or dissatisfied } \\
\text { - Satisfied }\end{array}$ & 0.29 & 0.00 & 0.15 & 0.43 \\
\hline
\end{tabular}

Abbreviations: BDS, Bachelor of Dental Surgery; DDS, Doctor of Dental Surgery; MSc, Master of Science; PhD, Doctor of Philosophy. 
benefits package related to insurance, retirement, and bonuses. Being satisfied as a dentist is crucial as it yields pleasure and motivation which in turn can have an effect on professional performance and subsequently patient care.

\section{Funding \\ None.}

\section{Conflict of Interest}

None declared.

\section{References}

1 Luzzi L, Spencer AJ, Jones K, Teusner D. Job satisfaction of registered dental practitioners. Aust Dent J 2005;50(3):179-185

2 Schwartz RH, Murray BP. Factors affecting work satisfaction among dentists in Utah: a secondary analysis. J Am Coll Dent 1981;48(1):47-58

3 Wilson RF, Coward PY, Capewell J, Laidler TL, Rigby AC, Shaw TJ. Perceived sources of occupational stress in general dental practitioners. Br Dent J 1998;184(10):499-502

4 Howard JH, Cunningham DA, Rechnitzer PA, Goode RC. Stress in the job and career of a dentist. J Am Dent Assoc 1976;93(3):630-636

5 Puriene A, Aleksejuniene J, Petrauskiene J, Balciuniene I, Janulyte V. Self-perceived mental health and job satisfaction among Lithuanian dentists. Ind Health 2008;46(3):247-252

6 Atalayin C, Balkis M, Tezel H, Onal B, Kayrak G. The prevalence and consequences of burnout on a group of preclinical dental students. Eur J Dent 2015;9(3):356-363

7 Bakker A, Demerouti E. Towards a model of work engagement. Career Dev Int 2008;13:209-223

8 Ali DA. Patient satisfaction in dental healthcare centers. Eur J Dent 2016;10(3):309-314

9 Schwartz RH, Shenoy S. Personality factors related to career satisfaction among general practitioners. J Dent Educ 1994;58(3):225-228

10 Cooper CL, Watts J, Kelly M. Job satisfaction, mental health, and job stressors among general dental practitioners in the UK. Br Dent J 1987;162(2):77-81

11 Jeong SH, Chung JK, Choi YH, Sohn W, Song KB. Factors related to job satisfaction among South Korean dentists. Community Dent Oral Epidemiol 2006;34(6):460-466

12 Fahim AE. Predictors of job satisfaction among practicing dentists at hospitals in Suez Canal Area, Egypt. Int J Occup Med Environ Health 2013;26(1):49-57

13 Seraj B, Ghadimi S, Mirzaee M, et al. Job satisfaction and its influential factors in dental academic members in Tehran, Iran. Ann Med Health Sci Res 2014;4(2):192-197

14 Al-Ali K, Hashim R. Occupational health problems of dentists in the United Arab Emirates. Int Dent J 2012;62(1):52-56
15 Hashim R, Al-Ali K. Health of dentists in United Arab Emirates. Int Dent J 2013;63(1):26-29

16 Abraham SB, Amini AM, Khorshed NE, Awad M. Quality of life of dentists. Eur J Dent 2018;12(1):111-115

17 Starkel R, Guay A, Losasso A, et al. Job satisfaction among dentists varies by type of large group practice setting. American Dental Association [Internet]; 2015. Available at: http://www. ada.org/ /media/ADA/Science\%20and\%20Research/HPI/Files/ HPIBrief_0815_1.ashx. Accessed January 24, 2019

18 Kaipa S, Pydi SK, Krishna Kumar RV, Srinivasulu G, Darsi VR, Sode M. Career satisfaction among dental practitioners in Srikakulam, India. J Int Soc Prev Community Dent 2015;5(1):40-46

19 Pandita V, Patthi B, Singh S, et al. Professional satisfaction among dental practitioners in Ghaziabad city. J Indian Assoc Public Health Dent. 2015;13:48

20 D'raven L, Raven N, Zaidi N. Happiness in the United Arab Emirates: conceptualisations of happiness among Emirati and other Arab students. Intl J Happiness Dev 2015;2:1

21 Khawaja M. UAE the Happiest Country in the Middle East UN Report [online]; 2012. Available at: http://arabiangazette. com/uae-happiest-middle-east-country/. Accessed September 13,2019

22 CroucherM. 'UAE's residents among the world's happiest, study finds' [online] 2013. Available at: https://www.thenational. ae/uae/uae-s-residents-among-the-world-s-happiest-studyfinds- 1.603563

23 Ayers KM, Thomson WM, Rich AM, Newton JT. Gender differences in dentists' working practices and job satisfaction. J Dent 2008;36(5):343-350

24 Bergström K, Söderfeldt B, Berthelsen H, Hjalmers K, Ordell S. Overall job satisfaction among dentists in Sweden and Denmark: a comparative study, measuring positive aspects of work. Acta Odontol Scand 2010;68(6):344-353

25 Harris RV, Ashcroft A, Burnside G, Dancer JM, Smith D, Grieveson B. Facets of job satisfaction of dental practitioners working in different organisational settings in England. Br Dent J 2008;204(1):E1-E1, discussion 16-17

26 Doshi D, Jain A, Vinaya K, Kotian S. Quality of life among dentists in teaching hospitals in South Canara, India. Indian J Dent Res 2011;22(4):552-555

27 Wig N, Lekshmi R, Pal H, Ahuja V, Mittal CM, Agarwal SK. The impact of HIV/AIDS on the quality of life: a cross sectional study in north India. Indian J Med Sci 2006;60(1):3-12

28 Barua A, Mangesh R, Harsha Kumar H, et al. A cross-sectional study on quality of life in geriatric population. Indian J Community Med 2007;32:146

29 Gorter RC, Freeman R. Burnout and engagement in relation with job demands and resources among dental staff in Northern Ireland. Community Dent Oral Epidemiol 2011; 39(1):87-95 